\title{
Quantitative and Qualitative Measures to Assess Organizational Inclusion: A Systematic Review
}

\author{
Molly O'Keefe \\ University of Louisville
}

Sonali S. Salunkhe

University of Louisville

Cameron Lister

University of Louisville

\author{
Christopher Johnson \\ University of Louisville
}

Theodore Edmonds

University of Louisville

An increase in workforce diversity emphasizes the value of testing approaches that assess workplace inclusivity. On conducting a systematic review of quantitative and qualitative measures used to evaluate organizational inclusion, a total of fifteen articles comprising eight measures, two models, and one framework were identified. Five common themes included: equal treatment from peers and supervisors; inclusion promoted at an organizational level; empowerment; uniqueness recognized and valued; and belongingness. This review supports the rationale for creating a new scientific process to support organizational efforts to reconfigure existing talent assets to navigate culturally-fluid business landscapes comprised of an increasingly diverse American workforce.

Keywords: organizational inclusion, diversity, inclusion, systematic review, measures, metrics, workforce, culture, well-being, human resources

\section{INTRODUCTION}

For the past several decades, diversity and inclusion have been the discussed in the empirical literature. Diversity focuses on bringing diverse groups, including women, people of color, disabled individuals, older workers, and people of other marginalized groups, into the workplace (Shore, Cleveland, \& Sanchez, 2018). In contrast, inclusion relates to producing equal access to resources, decision-making, and progress opportunities for these people (Shore, Cleveland, \& Sanchez, 2018). While diversity tends to focus on the fairness of organizational processes and how an organization treats minority employees, inclusion tends to 
focus on the engagement of individuals and learning from diverse perspectives (Nishii, 2013). An increase in diversity in the workforce emphasizes the value of testing approaches that assess workplace inclusivity (Shore, Cleveland, \& Sanchez, 2018). As stated by Mor Barak (2005, p. 7), an inclusive workplace is one that "(a) values and utilizes individual and intergroup differences within its workforce, (b) cooperates with, and contributes to, its surrounding community, (c) alleviates the needs of disadvantaged groups in its wider environment, and (d) collaborates with individuals, groups, and organizations across national and cultural boundaries." Workforce diversity is relatively easy to achieve and measure when compared to inclusion (Shore, Cleveland, \& Sanchez, 2018). Although diversity presents with the opportunity for innovation, without inclusion, the benefits of diversity are unlikely to manifest (Shore, Cleveland, \& Sanchez, 2018; Offerman \& Basford, 2014).

There are various available measures of inclusion in the literature; however, due to the sparsity of research, the reliability and validity of each of these measures is unclear. The objective of this systematic literature review is to identify the quantitative and qualitative measures, as well as theoretical frameworks studied over the past fifteen years that have been used to assess organizational inclusion.

\section{METHODS}

This systematic review was conducted according to the Preferred Reporting Items for Systematic Reviews and Meta-Analyses (PRISMA) guidelines (Moher et al., 2010). A search of PubMed, Business Source Premier, ABI/INFORM, Google Scholar, EBSCO Academic Search, and PsychInfo databases was conducted using the following keywords: employee inclusion, diversity and inclusion, diversity \& inclusion, inclusion, inclusivity, measure, metric, intervention, model, framework, index, instrument, survey, organization, employer, company, corporation, workplace, firm, and human resources (See Appendix 1). Studies were included if they were peer-reviewed, published in the United States after 2004, and discussed a workplace or organizational inclusion measure, scale, model, or framework. For the purpose of this review, inclusion was defined as "the degree to which individuals feel a part of the critical organizational processes, such as access to information, connectedness to co-workers and ability to participate in and influence the decision-making processes" (Mor Barak, 2011). Titles and abstracts were screened by authors for relevance, then full texts were retrieved and reviewed closely to determine pertinence. Relevant information from the full-text articles was summarized based on study population, intervention, comparison, and outcome (PICO), author, and year of publication. The articles were sorted into by the measure, scale, model, or framework employed in the study (See Table 1).

TABLE 1

MEASURE, SCALE, MODEL, OR FRAMEWORK EMPLOYED IN THE STUDY

\begin{tabular}{|c|c|c|c|}
\hline Measure or Framework & Type & Description & Cited by \\
\hline $\begin{array}{l}\text { Mor Barak Inclusion- } \\
\text { Exclusion Scale }\end{array}$ & Survey & $\begin{array}{l}15 \text { questions assessed on a six- } \\
\text { point Likert scale that evaluates the } \\
\text { degree to which individuals feel a } \\
\text { part of critical organizational } \\
\text { processes in relation to five } \\
\text { organizational system levels: work } \\
\text { group, organization, supervisor, } \\
\text { upper management, and } \\
\text { social/informal. The respondent is } \\
\text { asked to evaluate his or her } \\
\text { inclusion across three dimensions: } \\
\text { (1) the decision- making process, } \\
\text { (2) information networks, and (3) } \\
\text { level of participation/involvement. }\end{array}$ & $\begin{array}{l}\text { Brimhall et al. } \\
(2017) \text {. } \\
\text { Brimhall et al. (2014) } \\
\text { Cottrill et al. (2013). } \\
\text { Hwang and Hopkins } \\
(2012) \text {. }\end{array}$ \\
\hline
\end{tabular}




\begin{tabular}{|c|c|c|c|}
\hline $\begin{array}{l}\text { Workplace Social } \\
\text { Inclusion }\end{array}$ & Survey & $\begin{array}{l}3 \text { items assessed on a five-point } \\
\text { agree-disagree scale. Describes } \\
\text { extent to which employees have } \\
\text { informal ties with people in their } \\
\text { workplace, feel as though they } \\
\text { belong, and are socially included in } \\
\text { the workplace. }\end{array}$ & $\begin{array}{l}\text { Pearce and Randel } \\
(2004) .\end{array}$ \\
\hline Climate for Inclusion & Survey & $\begin{array}{l}\text { 31-item inclusion construct based } \\
\text { on } 3 \text { dimensions rated on five-point } \\
\text { Likert scale: fairly implemented } \\
\text { employment practices (9), } \\
\text { integration of differences (11), and } \\
\text { inclusion in decision making (11). }\end{array}$ & Nishii (2013). \\
\hline $\begin{array}{l}\text { New Inclusion Quotient } \\
\text { (IQ) from the Federal } \\
\text { Employment Viewpoint } \\
\text { survey }\end{array}$ & Survey & $\begin{array}{l}20 \text { questions grouped into } 5 \text { Habits } \\
\text { of Inclusion: Fair (5), Open (4), } \\
\text { Cooperative (2), Supportive (5), } \\
\text { and Empowering (4). } \\
\text { Developed by the U.S. Office of } \\
\text { Personnel Management. Described } \\
\text { as capturing behaviors that } \\
\text { "repeated over time, form the } \\
\text { habits that create the essential } \\
\text { building blocks of an inclusive } \\
\text { environment }\end{array}$ & $\begin{array}{l}\text { Liggans, et al. } \\
(2019) \text {. } \\
\text { Sabharwal et al. } \\
(2019) \text {. }\end{array}$ \\
\hline $\begin{array}{l}\text { Organizational Inclusion } \\
\text { Behaviors (OIB) }\end{array}$ & Survey & $\begin{array}{l}23 \text { items across } 3 \text { areas: } \\
\text { commitment from top leadership to } \\
\text { foster inclusion, ability of } \\
\text { employees to influence } \\
\text { organizational decisions, } \\
\text { fair/equitable treatment from } \\
\text { management. }\end{array}$ & Sabharwal (2014). \\
\hline $\begin{array}{l}\text { Model for Inclusive } \\
\text { Organizations }\end{array}$ & Model & $\begin{array}{l}\text { Multi-stage model based on a } \\
\text { review of the inclusion literature. } \\
\text { Includes top management } \\
\text { commitment to diversity and } \\
\text { inclusion, management focus on } \\
\text { enhancement of inclusion, } \\
\text { inclusion practices and processes, } \\
\text { and potential results of inclusion } \\
\text { climate, perceived inclusion, and } \\
\text { retention and expansion of talent. } \\
\text { Has not been empirically tested. }\end{array}$ & $\begin{array}{l}\text { Shore, Cleveland, } \\
\text { and Sanchez (2018). }\end{array}$ \\
\hline $\begin{array}{l}\text { Belongingness/Uniqueness } \\
\text { Inclusion Framework }\end{array}$ & Framework & $\begin{array}{l}\text { A } 2 \times 2 \text { framework based on feelings } \\
\text { of belongingness and uniqueness. } \\
\text { Separated into quadrants: } \\
\text { Exclusion (low belonging/low } \\
\text { uniqueness), assimilation (high }\end{array}$ & Shore et al. (2011). \\
\hline
\end{tabular}




\begin{tabular}{|c|c|c|c|}
\hline & & $\begin{array}{l}\text { belonging/low uniqueness), } \\
\text { differentiation (low belonging, high } \\
\text { uniqueness), and inclusion (high } \\
\text { belonging/high uniqueness). } \\
\text { Members want to be valued for } \\
\text { their high uniqueness and want } \\
\text { high belongingness to the group. }\end{array}$ & \\
\hline $\begin{array}{l}\text { Theory of Generative } \\
\text { Interactions }\end{array}$ & Model & $\begin{array}{l}\text { Complex model based on } 3 \\
\text { concepts: } 1 \text {. Inclusion is created } \\
\text { and sustained by org. practices of } \\
\text { generative interaction that provide } \\
\text { group and org. conditions for } \\
\text { prejudice-reducing, adaptive } \\
\text { contact among diverse individuals; } \\
\text { 2. Org. practices that sustain } \\
\text { adaptive contact operate in } \\
\text { combination; and 3. Particular org. } \\
\text { practices of generative interaction } \\
\text { serve as interrelated criteria for } \\
\text { predicting the outcomes of } \\
\text { diversity in a particular context. }\end{array}$ & $\begin{array}{l}\text { Bernstein et al. } \\
(2019) \text {. }\end{array}$ \\
\hline Downey Inclusion scale & Survey & $\begin{array}{l}\text { 10-item scale used to evaluate the } \\
\text { employee's perceptions of } \\
\text { inclusion assessed on a five-point } \\
\text { Likert scale ranging from } 1 \\
\text { (strongly disagree) to } 5 \text { (strongly } \\
\text { agree). Article does not provide } \\
\text { full scale. }\end{array}$ & $\begin{array}{l}\text { Downey et al. } \\
(2015) \text {. }\end{array}$ \\
\hline Work Group Inclusion & Survey & $\begin{array}{l}\text { 10-item scale based on Shore's } \\
\text { belongingness/uniqueness } \\
\text { framework of inclusion. Measured } \\
\text { on a 5-point Likert type scale. }\end{array}$ & Chung et al. (2019). \\
\hline $\begin{array}{l}\text { Individual Inclusion } \\
\text { Experience }\end{array}$ & Survey & $\begin{array}{l}\text { 4-item scale developed to test } \\
\text { diverse board members' perceived } \\
\text { inclusion in comparison to } \\
\text { diversity and inclusion practices. } \\
\text { Assessed using a four-item Likert } \\
\text { scale. }\end{array}$ & $\begin{array}{l}\text { Bernstein and } \\
\text { Bilimoria. (2012). }\end{array}$ \\
\hline
\end{tabular}

\section{RESULTS}

As shown in Figure 1, we identified eleven individual measures, models, or frameworks that assessed organizational inclusion across fifteen studies, including eight individual scales and three models or frameworks. After an initial result of 647 articles, 194 remained after a title review, and 48 after an abstract review. Of the 48 articles, fifteen articles were identified that discuss an inclusion measure, model, or framework in workplace or organizational settings within the United States over the past 15 years. 
FIGURE 1

PRISMA FLOWCHART

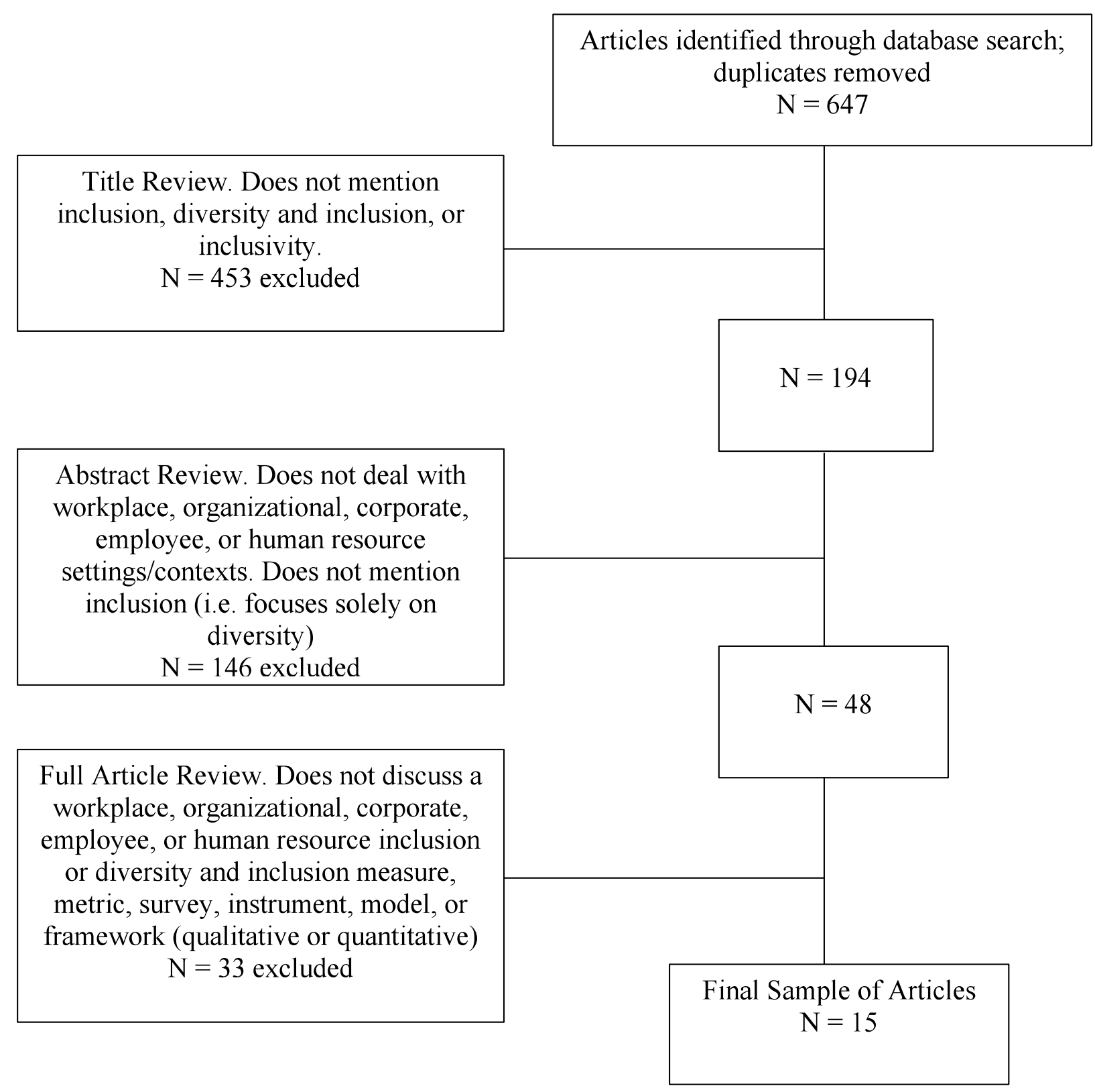

\section{Inclusion/Exclusion Scale}

Of the fifteen studies included in the review, four employed the 15-item Mor Barak Inclusion-Exclusion scale, created by Mor Barak and Cherin (1998) and later updated by Mor Barak (2005) (See Appendix 2). The Inclusion/Exclusion Scale asks fifteen questions that evaluate an individual's sense of inclusion in relation to five system levels: work group, organization, supervisor, upper management, and social/informal. Each of the levels are categorized based on the individual's sense of inclusion in decisionmaking processes, information networks, and level of participation. The instrument uses a 6-point Likert scale ranging from 1 (strongly agree) to 6 (strongly disagree) with higher scores representing a higher sense of inclusion felt by an individual. 
Brimhall, Lizano, and Mor Barak (2014) engaged the Inclusion/Exclusion scale in a study on the effects of workplace relationships and a climate of diversity and inclusion on employee job satisfaction and intention to leave the organization. Data was collected twice, at baseline from a sample of 364 child welfare workers and during a six-month follow-up from a remaining sample of 187 workers. The InclusionExclusion scale was used in conjunction with several other measures of Leader-Member Exchange (LMX), job satisfaction, diversity perceptions, and employee intention to leave. The study found was a significant indirect effect of LMX on job satisfaction as employees who perceived a higher-quality relationship with their supervisors had increased job satisfaction through increased feelings of inclusion. Using the same data set, Brimhall, et al. (2017) engaged the Inclusion/Exclusion scale to examine whether organizational leaders can influence inclusion and whether LMX affected how feelings of inclusion changed over time. The study examined the employees at a public child welfare organization in three intervals over 12 months, with 187 remaining at Interval 2 and 133 remaining at Interval 3. The study found that employee perception of inclusion increases over time and that high LMX scores, indicating higher-quality leader-follower relationships, was associated with higher inclusion scores.

Next, Hwang and Hopkins (2012) employed the Inclusion/Exclusion scale, with two other measures of organizational commitment and turnover intention, to assess whether organizational commitment mediated the effects of inclusion on employee turnover intention among a sample of child welfare workers. This study used only eight items and a five-point Likert scale instead of the fifteen items and six-point Likert scale used in the Inclusion/Exclusion scale (Mor Barak, 2005; Mor Barak \& Cherin, 1998). It found that organizational commitment mediates the effect of inclusion on turnover intention among workers, meaning that organizational commitment reduces the link between a low level of inclusion and high level of turnover intention. Lastly, Cottrill, Lopez, and Hoffman (2013) also used the Inclusion/Exclusion scale in their study of the relationship between inclusion and authentic leadership (AL), two potential outcomes potentially related to inclusion, organizational citizenship behavior (OCB) and organization-based self-esteem (OBSE). AL, OCB, and OBSE. In a sample of 107 primary participants across various industries, the study found a positive relationship between inclusion and $\mathrm{AL}, \mathrm{OBSE}$, and self-rated OCB respectively. The authors suggest that organizations can promote inclusion through AL and that AL may promote OBSE.

\section{Workplace Social Inclusion}

Pearce and Randel created the Workplace Social Inclusion (WSI) scale, a three-item survey on a fivepoint Likert scale ranging from 1 (strongly agree) to 5 (strongly disagree) with higher scores representing a higher sense of inclusion. In a study on the relationship between Expectation of Organizational Mobility (EOM) and workplace inclusion (See Appendix 3). WSI describes the extent to which employees have informal ties with people in their workplace, feel as though they belong, and are socially included in the workplace. In a sample of 557 employees from two different organizations, the authors found that the greater an employee's EOM, the lower his or her WSI. Lower WSI, in turn, was associated with a lower job performance rating. No other studies that use WSI as a measure of organizational inclusion were identified.

\section{Climate for Inclusion}

In a study of whether inclusion can moderate the link between gender diversity and conflict, Nishii (2013) created the Climate for Inclusion construct, a 31-item survey on a five-point Likert scale ranging from 1 (strongly agree) to 5 (strongly disagree) based on three dimensions: fairly implemented employment practices (nine items), integration of differences (eleven items), and inclusion in decision making (eleven items) (See Appendix 4). Nishii found in a study sample of 1324 that relationship and task conflict are significantly lower in gender-diverse groups with higher Climate for Inclusion scores. Further, high climate for inclusion scores mitigate the negative association between relationship conflict and unit-level satisfaction. No other studies that use Climate for Inclusion scale as a measure of organizational inclusion were identified. 


\section{New Inclusion Quotient}

The New Inclusion Quotient (New IQ), employed by two identified studies, is a twenty-item scale developed by the United States Office of Personnel Management in 2014 for use within the Federal Employee Viewpoint Survey (FEVS), a voluntary, web-based 98-item survey (See Appendix 5). FEVS measures federal employees' "perceptions of whether, and to what extent, conditions characteristic of successful organizations are present in their agencies," and is distributed annually to full- and part-time federal employees of departments and large agencies, as well as small and independent agencies that choose to participate (OPM, 2019). Employees are asked to grade how "Fair" (five items), "Open" (four items), "Cooperative" (two items), "Supportive" (five items), and "Empowering" (four items) they feel their workplaces are. These items, referred to as "Habits of Inclusion" are assessed on a three-point scale, indicating whether the respondent feels (1) negative, (2) neutral, or (3) positive about the item. While only two studies identified in this review employ items from the New IQ scale, it is distributed to a far greater number of individuals than any other measure.

Sabharwal et al. (2019) employed the New IQ items from the 2015 FEVS to assess turnover intentions among federal lesbian, gay, bisexual, and transgender (LGBT) employees and the moderating effect of inclusion and agency type on turnover intention. A total of 421,748 employees responded to the 2015 survey from 82 agencies, 37 large agencies, and 45 small/independent agencies. Liggans et al. (2019) employed four of the twenty New IQ items to examine the relationship between organizational inclusion, human resource practices, trust in leadership, and organizational commitment among military veterans and nonveterans in federal agencies. In a sample of $206,321-30 \%$ veterans and $70 \%$ nonveterans - the authors found that organizational inclusion had more of an impact on trust in leadership among veterans than nonveterans. Similar to Sabharwal et al. (2019), the authors in this study also used data from the 2015 FEVS.

\section{Organizational Inclusion Behaviors}

Sabharwal (2014) created a 23-item scale to measure Organizational Inclusion Behaviors (OIB) in a study of the moderating effects of diversity management and inclusion on organizational performance (See Appendix 6). Citing Mor Barak and Cherin (1998), the author defines OIB as "the degree to which individuals feel part of critical organizational processes,' indicated by work group involvement, access to information and resources, and the ability to influence decision-making." OIB is conceptualized in three areas: commitment from top leadership to foster inclusion, ability of employees to influence organizational decisions, and fair/equitable treatment from management. In a sample of 198 employees from Texas governmental agencies, the author found that, while diversity management did not predict organizational performance, among the OIB measures, commitment from leadership and ability to influence work group decisions are positively associated with perceived organizational performance.

\section{Model for Inclusive Organizations}

Shore, Cleveland, and Sanchez (2018) review the inclusion literature and propose a multi-stage model for inclusive organizations that argues inclusive treatment of all employees, coupled with opportunities to advance to mid- and upper-levels of an organization, are necessary to establish an inclusive organization (See Appendix 7). The authors posit that organizations have two potential processes to contribute to organizational inclusion - management prevention orientation and management promotion orientation. In the former, managers focus on averting exclusion for the safety and security of the organization and focus on compliance practices and policies, which can result in an inclusive climate. In a promotion orientation, managers actively pursue inclusion, and focus on six inclusion practices and processes: 1) psychological safety, 2) involvement in work groups, 3) feeling respected and valued, 4) influence on decision making, 5) authenticity, and 6) respecting, honoring, and advancement of diversity. These practices and processes, the authors pose, can result in perceived inclusion and retention and expansion of talent, in addition to an inclusion climate. The model does not provide ways to measure inclusion and it is not clear if it has been employed in any subsequent studies. 


\section{Belongingness/Uniqueness Inclusion Framework}

Shore et al. (2011) reviewed the inclusion literature and consider Optimal Distinctiveness Theory (ODT), which explains that humans need validation and similarity to others and, on the other hand, also need uniqueness and individuation, and balance these needs through an optimal level of inclusion in groups (Brewer, 1991). Considering the inclusion literature and ODT, the author proposes a $2 \times 2$ framework of inclusion in which uniqueness and belongingness work together to create inclusion. The framework proposes that if a member of a group feels low belongingness and the group does not value that individual's uniqueness, he or she will experience exclusion (See Appendix 8). If there is low belongingness and a high value on uniqueness, the individual will experience differentiation, in which he or she is not treated as an insider but his or her unique characteristics are seen as valuable. High belongingness and a low value on uniqueness results in assimilation, in which the individual is treated as an insider when he or she conforms to the dominant culture and downplays unique characteristics. Lastly, the framework poses that an individual will experience inclusion when he or she experiences high belongingness and the group highly values uniqueness because the individual will be able to embrace his or her unique characteristics while remaining an insider. The author does not propose any measures to assess levels of belonging or uniqueness and it does not appear the framework has been employed in any further studies, though its key tenets were used to develop Chun et al.'s (2019) ten-item measure of work group inclusion, discussed later.

\section{Theory of Generative Interactions}

Bernstein et al. (2017) propose the Theory of Generative Interactions which suggests that in order to create inclusion, exclusionary dynamics must be overcome through generative interactions that create social connection and a deep understanding necessary to create equity at an organizational level. The authors pose that superficial interactions are not sufficient to move organizations from diversity to inclusion. There is no "one-size-fits-all" solution and the theory is meant to be applied contextually based on three precepts: (1) inclusion is created and sustained by organizational practices of generative interaction that provide group and organizational conditions for contact among diverse individuals; (2) organizational practices that sustain adaptive contact must operate in tandem as a set; and (3) particular organizational practices of generative interaction serve as criteria for predicting the outcomes of representational diversity in a particular context. There are no proposed measures to assess whether generative interactions have been achieved or sustained and it does not appear the framework has been employed in any further studies.

\section{Downey Inclusion Scale}

In a study of the association between diversity practices and employee engagement, Downey et al. (2015) developed a ten-item inclusion scale based on Roberson (2006), in which the author competitively investigates meanings of diversity and inclusion. This scale was used in conjunction with measurements for trust climate, employee engagement, and diversity practices. While the study did not provide all ten items used in the inclusion scale, it provided several examples, included in Appendix 9. Using a sample of 4,597 health sector employees, the study concluded diversity practices are associated with a climate of trust which is in turn positively associated with employee engagement. Further, inclusion moderated the relationship between trust climate and diversity practices; specifically, that positive perceptions of diversity practices were related to trust climate only when a high level of inclusion was present. There is no indication the measure developed by Downey et al. (2015) has been used since this study.

\section{Work Group Inclusion Scale}

Chung et al. (2019) developed the Work Group Inclusion scale, a ten-item measure using a five-point Likert scale ranging from 1 (strongly disagree) to 5 (strongly agree), based on the key tenets of Shore et al.'s (2011) belongingness-uniqueness framework of inclusion (See Appendix 10). The study uses the framework to develop, validate, and refine a measure that reflects the framework's core tenets. After testing the measure on a sample of 806 with several other measures, the authors found that diversity climate and leader inclusiveness predicted work group inclusion. Work group inclusion predicted helping, creativity, 
and job performance. There is no indication the measure developed by Downey et al. (2015) has been used since this study.

\section{Individual Inclusion Experience}

Bernstein and Bilimoria (2012) assess how an organization's board diversity affects organization and board practices and behaviors and impacts board members' experiences on inclusion. The authors developed a four-item scale to test diverse board members' perceived inclusion in comparison to diversity and inclusion practices. The study did not provide exact wording for the items developed but did provide that "Respondents were asked to indicate the extent to which they were comfortable voicing ideas, opinions, and discussing issues of diversity, felt valued and encouraged to be themselves by other board members, and felt they had the same opportunities as others for leadership and officer positions" (Bernstein and Bilimoria, 642; See Appendix 11). Responses were recorded using a four-item Likert scale ranging from 1 (never) to 4 (almost always). In a sample of 403 racial/ethnic minority board members, the study found that board members had increased feelings of inclusion as board attitudes towards diversity and inclusion moved from a discrimination and fairness perspective, in which the board seeks to treat all members equally, to an access and legitimacy perspective, predicated on the acceptance and celebration of differences. Inclusion increased again when board attitudes shifted from the access and legitimacy perspective to the integration and learning perspective, in which the board views diversity as contributing beneficial perspectives and approaches from which all employees can benefit.

\section{DISCUSSION}

Compelling business motives exist for organizations to commit to doing the hard work of creating inclusive workplace cultures. Companies with inclusive cultures are twice as likely to meet financial goals, three times as likely to be high performing, six times as likely to be innovative and agile, and eight times more likely to achieve better business outcomes (Bourke, 2016).

Many of the current corporate models focused on achieving diversity, and inclusion in the workplace fail to recognize that each is a distinct goal. Achieving diversity does not guarantee inclusion. Diversity is a policy output, a necessary, precedent, threshold number to be achieved on the road to inclusion. Inclusion, however, is an iterative, dynamic cultural process that is always evolving in response to social and environmental forces. Culture is the blueprint responsible for a particular population group's actions, and is used to live life and make informed decisions (Kao et al., 2004; Swidler, 1986 as cited in Kagawa, 2012). Although several different definitions of culture exist, four essential characteristics of culture include: 1) acquired from birth by language acquisition and socialization, 2) shared by everyone belonging to the same cultural group, 3) compliance to particular environmental and technical conditions and 4) a progressive and evolving process (Dibble, 1983; Kagawa-Singer, 2006; Kagawa-Singer et al., 2010; Leininger, 1995 as cited in Kagawa, 2012). Just checking a "diversity box" to confirm a business has a requisite number of minority employees or certain kinds of policies can lead to a potentially false construct which, in many cases, may miss the point of diversity and inclusion efforts: to utilize the untapped resources of employees who have been historically excluded or underestimated such as Black and Indigenous people of color (BIPOC), LGBTQ+, women, and others.

Forbes reports that organizations spend about $\$ 8$ billion per year on diversity and inclusion (D\&I) training with little to show for their efforts (Elsesser, 2019). Forbes states, "Not only do traditional diversity programs not work, but recent research (Dobbin \& Kalev, 2016) shows that they can even have a negative effect on diversity outcomes. That is, they may actually lead to less diversity within the organization. If that's not bad enough, the training may even reinforce stereotypes about a particular race or gender" (Elsesser, 2019).

An overwhelming amount of research in the diversity and inclusion space focuses solely on diversity and diversity management or conflates diversity and inclusion. Diversity and inclusion are unique, overlapping concepts (Roberson, 2006). Inclusion goes beyond diversity. While there are available measures of inclusion in the literature, the sparsity of research makes it unclear how valid each measure is 
or if multiple measures are needed to reflect different components inclusion. The majority of measure items ask employees to self-report how they feel in the workplace. This approach does not account for the individual's cultural identity outside of the workplace which mediates how an individual may interpret the inclusion efforts of an organization, whether or not the efforts are seen as beneficial, and, ultimately, whether or not the individual will be motivated to comply in a way which delivers the organizational benefits of increased innovation and productivity in its workforce, the ultimate goal of inclusion programs. "As adults, humans have been variously calibrated, psychosocially, to a particular cultural, social, or national perspective, its representations, and world view. In a nation or culture, inculcated norms, values, and practices endure to the extent that they are useful, psychologically, sociopolitically, economically, and spiritually" (Hoare, 2008, pp. 86).

While the reviewed measures and frameworks try to predict whether an employee feels included, the metrics do not explain why. In other words, there is a gap in knowledge on how culture outside the workplace influences the perceptions of how inclusive culture inside the workplace, and vice versa. More empirical research is needed to develop the body of knowledge that can inform businesses and organizations on best practices for inclusion in the workplace (Roberson, 2006). Understanding inclusion as a cultural challenge is the key to unlocking its potential for delivering a strategic or operational advantage for a business or other type of employer.

Recent reports from TechStars, Deloitte, U.S. Chamber of Commerce Foundation, Human Rights Campaign Equality Index all found that culture is key to innovation output and market performance (Smith \& Yoshino, 2019; "Techstars Startup Ecosystems Development Program", 2019; "U.S. Chamber of Commerce Foundation", 2019; "Human Rights Campaign Foundation", 2019). However, traditional culture surveys are lacking in their design: "Leaders can shape and manage culture - if they identify and measure it correctly. Most culture survey tools put organizations into types or categories - but they cannot connect a distinctive culture and business outcomes. Only a rigorous, science-based approach can validate that culture change is making a difference" ("The Gallup Corporation", 2018).

\section{Summary of Findings}

Several commons themes were identified across the various inclusion measures, models, and framework identified: (1) equal treatment from peers and supervisors; (2) inclusion promoted at an organizational level; (3) empowerment; (4) uniqueness recognized and valued; and, (5) belongingness. These five broad themes were found across the eleven measures, models, or frameworks of inclusion identified in this review. The New IQ, the measure likely distributed on the largest population due to its nature as an annual survey of federal employees, included items identifying with all of these themes. The Mor Barak Inclusion/Exclusion scale, used the most within the studies identified, included items identifying with every theme except uniqueness recognized and valued

Within the fifteen studies identified, there were eight individual scales and three models or frameworks. Notably, only two scales - the Mor Barak Inclusion Exclusion Scale and the New Inclusion Quotient were employed in more than one study. The models or frameworks identified - the Model for Inclusive Organizations, Belongingness/Uniqueness Inclusion Framework, and Theory of Generative Interactions model - were unique to the studies in which they were presented. The remaining six articles employed scales unique to each study and further evidence could not be found that any of the six were employed in subsequent studies.

\section{Common Themes}

Several broad themes were identified across the inclusion measures, frameworks, and models (See Table 2). 


\section{TABLE 2}

\section{COMMON THEMES}

\begin{tabular}{|l|l|}
\hline Equal treatment from peers and supervisors & New Inclusion Quotient \\
& Climate for Inclusion Scale \\
& Organizational Inclusion Behaviors Scale \\
& Downey Inclusion Scale \\
& Model for Inclusive Organizations \\
& Individual Inclusion Experience \\
& Mor Barak Inclusion-Exclusion Scale \\
\hline Inclusion promoted at an organizational level & New Inclusion Quotient \\
& Climate for Inclusion Scale \\
& Organizational Inclusion Behaviors Scale \\
& Belongingness/Uniqueness Inclusion Framework \\
& Theory of Generative Interactions \\
& Model for Inclusive Organizations \\
& Mor Barak Inclusion-Exclusion Scale \\
\hline Feeling of Empowerment & New Inclusion Quotient \\
& Climate for Inclusion Scale \\
& Organizational Inclusion Behaviors Scale \\
& Downey Inclusion Scale \\
& Model for Inclusive Organizations \\
& Individual Inclusion Experience \\
& Mor Barak Inclusion-Exclusion Scale \\
\hline Sniqueness recognized and valued & New Inclusion Quotient \\
& Climate for Inclusion Scale \\
& Belongingness/Uniqueness Inclusion Framework \\
& Work Group Inclusion Measure \\
& Downey Inclusion Scale \\
& Individual Inclusion Experience \\
\hline & New Inclusion Quotient \\
& Workplace Social Inclusion Scale \\
& Climate for Inclusion Scale \\
& Belongingness/Uniqueness Inclusion Framework \\
& Work Group Inclusion Measure \\
& Individual Inclusion Experience \\
& Mor Barak Inclusion-Exclusion Scale \\
\hline
\end{tabular}

\section{Inclusion Theme One: Equal Treatment From Peers and Supervisors}

First, seven of the measures, models, or frameworks included an item assessing the extent to which individuals received equal treatment from their peers and supervisors. These items inquire about whether organizations treat employees objectively, provide equal opportunity for input and advancement, and reward employees based on the merits. The New IQ scale, for example, has six items assessing whether employees are treated equally including "Awards in my work unit depend on how well employees perform their job" and the Organizational Inclusion Behaviors Scale includes nine items on fairness/equitable treatment including "My supervisor assigns tasks based on the knowledge, skills, and abilities possessed by individual employees," (Sabharwal, 2014). To provide another example, the Downey Inclusion Scale asks whether "All viewpoints, including those that differ from the majority opinion, are considered before decisions are made by [the organization]" (Downey et al., 2015). 


\section{Inclusion Theme Two: Inclusion Promoted at an Organizational Level}

Seven of the measures, models, or frameworks include items assessing whether inclusion was promoted at an organizational level, which includes organizational policies and practices that promote inclusion and actions by upper leadership which demonstrate a commitment to inclusion. For example, the Theory of Generative Interactions focuses primarily on ways in which organizations orchestrate positive interactions among employees, encourage adaptive contact among diverse persons, and use such practices as the criteria to determine the outcomes of diversity efforts. The Mor Barak Inclusion/Exclusion Scale includes three item on Higher Management, such as "I am often invited to participate in meetings with management high than my immediate supervisor," and the New Inclusion Quotient asks whether "Policies and programs promote diversity in the workplace (for example, recruiting minorities and women, training in awareness of diversity issues, mentoring)" (Mor Barak, 2005).

\section{Inclusion Theme Three: Feeling of Empowerment}

Seven of the measures, models, or frameworks assessed the extent to which individuals felt empowered, which describes the extent to which they feel they have access to the proper resources, opportunity for input, impact in the workplace, and an opportunity to advance. This component is important because it is a major factor in differentiating bare diversity, in which organizations employ minority employees without making an effort to incorporate or value their diverse experiences and opinions, from diversity with inclusion, in which all employees feel they have equal opportunity to contribute. Without empowerment, diversity efforts will fail to reap the benefits of the diversity of opinions and experiences of all employees because some will not feel comfortable enough to contribute. The Climate for Inclusion scale, for example, includes "It is clear that this [unit] perceives employee input as a key to its success" and the Downey Inclusion Scale includes "I believe that I play an important role in helping to shape the policies, procedures, and practices of [the organization]" (Nishii, 2013; Downey et al., 2015). The New IQ scale also has four items assessing the extent to which individuals feel empowered, including "I have enough information to do my job well" and "Employees have a feeling of personal empowerment with respect to work processes" (Sabharwal et al., 2019).

\section{Inclusion Theme Four: Uniqueness Recognized and Valued}

Six of the measures, models, or frameworks included items which assessed an individual's feeling that uniqueness is recognized and valued in the workplace. This means that individuals feel that the unique qualities, experiences, and opinions will be embraced by their peers, supervisors, and organizations. The Shore et al. (2011) Belongingness/Uniqueness Inclusion Framework, for example, posits that inclusion occurs when individuals feel both that they are insiders in the workplace and that their unique differences are embraced and valued by the group as a whole. Building on the work of Shore et al. (2011), the Work Group Inclusion scale asks five items to gauge the extent to which an individual feels his or her uniqueness is valued in the work place, such as "I can bring aspects of myself to this work group that other in the group don't have in common with me" (Chung et al., 2019).

\section{Inclusion Theme Five: Belongingness}

Lastly, seven of the measures, models, or frameworks included items which assessed an individual's sense of belonging, which describes the extent to which individuals feel they belong in their workplaces or work groups. The Work Group Inclusion scale, based on the Belongingness/Uniqueness Inclusion Framework, asks five items to gauge the extent to which individuals feel as though they belong in the workplace, such as "I belong in my work group," and "I feel that people really care about me in my work group" (Shore et al., 2011; Chung et al., 2019). The Mor Barak Inclusion/Exclusion Scale asks respondents to items specifically on social and informal interactions at work, such as "I am always informed about informal social activities and company social events" (Mor Barak, 2005). 


\section{Limitations}

Examining the inclusion literature, it is clear that the lack of available metrics and models impacts the validity of the conclusions drawn on the studies identified alone. As such, there were several limitations to this review that must be noted. First, studies were limited to peer-reviewed, English-language articles written in the United States after 2004. The items from the identified measures and components of the identified models and metrics were sorted into broad themes by one author and verified by another. Although each agreed on the themes found within the measures, models, and frameworks, the process was subjective and may have different results when conducted by an outside, unbiased party. Additionally, two articles, while examining different outcomes, are based on the same dataset. Overall, there is a lack of available research on inclusion, independent from diversity, and results may be skewed by this fact.

\section{CONCLUSION}

The themes identified in this systematic review provide a solid basis for assessing and creating measures, models, and frameworks in the future. Due to the research studies' sparsity, there is a lack of set standards for measuring inclusion in the workplace. Therefore, there is a need for more robust metrics that can be employed to study the impact of inclusion and a sense of belonging across several vital indicators: employee engagement, innovation output, organizational performance, employee wellbeing, and many more. Furthermore, notably, none of the measures, frameworks, or models incorporate inclusion outside of the workplace or organization setting. While some assessed social interactions within the workplace or with colleagues, none gauge an individual's wellbeing or feelings of inclusion outside the workplace. Further, none of the measures allowed space for individuals to expound on why they feel or do not feel included in their organizations and what factors they feel impact such feelings. Such measures may be missing a valuable opportunity to gather feedback from employees and learn how they may feel more included. This systematic literature review supports the rationale for the creation of a new scientific process to support organizational efforts to reconfigure existing talent assets in a way that successfully navigates culturallyfluid business landscapes comprised of an increasingly diverse American workforce.

Due to the lack of substantial studies, there appears to be no set standard for measuring inclusion in the workplace. Conducting more scientific studies toward the creation of robust, replicable, scalable metrics which get at the heart of inclusion and belonging in the workplace could prove highly beneficial to employers. Especially studies that causally link inclusion to impact across several key performance indicators such as employee engagement, employee retention, employee health and wellbeing, innovation output and company performance.

Precision in data could help companies better understand how their workforce constructs identity and map the competing value systems at play to unlock diverse talent who operate differently from dominant cultural frames. The main issue of concern is to be able to measure the right things to implement meaningful changes that result in more inclusive workplaces, thus positively impacting organizational performance and improving employee wellbeing. Single indicator metrics fail to capture the myriad of inputs that shape culture. We call for a multi-factor metric with predictive capabilities for key performance indicators core to business functioning, such as employee retention, satisfaction, engagement, health, innovation capacity, etc. -- which can also serve as a scientific proxy indicator of how inclusive an organization's culture actually feels for diverse employee groups.

Being strategic about inclusion requires looking at an employee workforce holistically. It requires understanding the systems that make up the experience of a whole individual and the interdependencies between work and society. It requires navigating the myriad of cultural identities that inform how employees will respond in unpredictable times. By strengthening the underlying internal culture of a business and better understanding the potential external cultural shocks and chronic cultural stresses that are constantly at play in the 21 st century, companies can improve innovation capacity and market performance while bolstering up cultures of inclusivity and wellbeing for diverse groups of employees. 


\section{ACKNOWLEDGEMENTS}

This report was guided by and developed with the assistance of Home Instead Senior Care. This manuscript is based upon work supported by the National Science Foundation under Grant No.1738359. Any opinions, findings, and conclusions or recommendations expressed in this material are those of the authors and do not necessarily reflect the views of the National Science Foundation.

\section{REFERENCES}

Bernstein, R.S., \& Bilimoria, D. (2013). Diversity perspectives and minority nonprofit board member inclusion. Equality, Diversity and Inclusion: An International Journal, 32(7), 636-653. https://doi.org/10.1108/EDI-02-2012-0010

Bernstein, R.S., Bulger, M., Salipante, P., \& Weisinger, J.Y. (2019). From diversity to inclusion to equity: a theory of generative interactions. Journal of Business Ethics, 167(3), 395-410. https://doi.org/10.1007/s10551-019-04180-1

Bourke, J. (2016). Which two heads are better than one?: How diverse teams create breakthrough ideas and make smarter decisions. Sydney, N.S.W.: Australian Institute of Company Directors.

Brewer, M.B. (1991). The social self: on being the same and different at the same time. Personality and Social Psychology Bulletin, 17(5), 475-482. https://doi.org/10.1177/0146167291175001

Brimhall, K.C., Lizano, E.L., \& Mor Barak, M.E. (2014). The mediating role of inclusion: a longitudinal study of the effects of leader-member exchange and diversity climate on job satisfaction and intention to leave among child welfare workers. Children and Youth Services Review, 40, 79-88. https://doi.org/10.1016/j.childyouth.2014.03.003

Brimhall, K.C., Mor Barak Michàlle, E., Hurlburt, M., McArdle, J.J., Palinkas, L., \& Henwood, B. (2017). Increasing workplace inclusion: the promise of leader-member exchange. Human Service Organizations: Management, Leadership \& Governance, 41(3), 222-239. https://doi.org/10.1080/23303131.2016.1251522

Chung, B.G., Randel, A.E., Dean, M.A., Ehrhart, K.H., Shore, L.M., \& Kedharnath, U. (2019). Work group inclusion: Test of a scale and model. Group and Organization Management, 45(1), 75102. https://doi.org/10.1177/1059601119839858

Cottrill, K., Denise Lopez, P., \& Hoffman, C. (2014). How authentic leadership and inclusion benefit organizations. Equality, Diversity and Inclusion: An International Journal, 33(3), 275-292. https://doi.org/10.1108/EDI-05-2012-0041

Dibble, C. (1983). Epilogue Educational Psychology 636: Cross-cultural Counseling. University of Utah, Educational Psychology Department, Salt Lake City, UT.

Dobbin, F., \& Kalev, A. (2016). Why diversity programs fail. Harvard Business Review, 94(7/8), 52-61.

Downey, S.N., Werff, L., Thomas, K.M., \& Plaut, V.C. (2015). The role of diversity practices and inclusion in promoting trust and employee engagement. Journal of Applied Social Psychology, 45(1), 35-44. https://doi.org/10.1111/jasp. 12273

Elsesser, K. (2019, January). Is This the Answer to Diversity and Inclusion? Retrieved from https://www.forbes.com/sites/kimelsesser/2019/01/28/is-this-the-answer-to-diversity-andinclusion/\#1a60d0a7523f

Hoare, C. (2008). Models of Adult Development in Bronfenbrenner's Bioecological Theory and Erikson's Biopsychosocial Life Stage Theory: Moving to a More Complete Three-Model View. In M. Smith (Ed.), \& N. DeFrates-Densch, Assistant Editor (Ed.), Handbook of Research on Adult Learning and Development (p.86). New York: Routledge. https://doi.org/10.4324/9780203887882

Human Rights Campaign Foundation. (2019). Corporate Equality Index 2019. Rating Workplaces on Lesbian, Gay, Bisexual, Transgender and Queer Equality. Retrieved from https://assets2.hrc.org/files/assets/resources/CEI-2019-FullReport.pdf 
Hwang, J., \& Hopkins, K. (2012). Organizational inclusion, commitment, and turnover among child welfare workers: A multilevel mediation analysis. Administration in Social Work, 36(1), 23-39. https://doi.org/10.1080/03643107.2010.537439

Kagawa, S.M. (2012). Applying the concept of culture to reduce health disparities through health behavior research. Preventive Medicine, 55(5), 356-61.

https://doi.org/10.1016/j.ypmed.2012.02.011

Kagawa-Singer, M. (2006). Population science is science only if you know the population. Journal of cancer education: The official journal of the American Association for Cancer Education, 21(1 Suppl), S22-S31. https://doi.org/10.1207/s15430154jce2101s_6

Kagawa-Singer, M., Dadia, A.V., Yu, M.C., \& Surbone, A. (2010, Jan-Feb). Cancer, culture, and health disparities: time to chart a new course? CA Cancer J. Clin., 60(1), 12-39.

Kao, H-F.S., Hsu, M-T., \& Clark, L. (2004). Conceptualizing and Critiquing Culture in Health Research. Journal of Transcultural Nursing, 15(4), 269-277. https://doi.org/10.1177/1043659604268963

Liggans, G., Attoh, P.A., Gong, T., Chase, T., Russell, M.B., \& Clark, P.W. (2019). Military veterans in federal agencies: organizational inclusion, human resource practices, and trust in leadership as predictors of organizational commitment. Public Personnel Management, 48(3), 413-437. https://doi.org/10.1177/0091026018819025

Moher, D., Liberati, A., Tetzlaff, J., \& Altman, D.G. (2010). Preferred reporting items for systematic reviews and meta-analyses: the prisma statement. International Journal of Surgery, 8(5), 336341. https://doi.org/10.1016/j.ijsu.2010.02.007

Mor Barak, M.E. (2005). Managing diversity: Toward a globally inclusive work- place. Thousand Oaks, CA: Sage.

Mor Barak, M.E. (2011). Managing diversity: Toward a globally inclusive work- place. Thousand Oaks, CA: Sage.

Mor Barak, M.E. (2014). Managing diversity: Toward a globally inclusive work- place. Thousand Oaks, CA: Sage.

Mor Barak, M.E., \& Cherin, D.A. (1998). A tool to expand organizational under- standing of workforce diversity: Exploring a measure of inclusion-exclusion. Administration in Social Work, 22(1), $47-$ 64. https://doi.org/10.1300/J147v22n01_04

Nishii, L.H. (2013). The benefits of climate for inclusion for gender-diverse groups. Academy of Management Journal, 56(6), 1754-1774. https://doi.org/10.5465/amj.2009.0823

Nishii, L.H., \& Mayer, D.M. (2009). Do inclusive leaders help to reduce turnover in diverse groups? the moderating role of leader-member exchange in the diversity to turnover relationship. The Journal of Applied Psychology, 94(6), 1412-1426. https://doi.org/10.1037/a0017190

Offerman, L.R., \& Basford, T.E. (2014). Best practices and the changing role of human resources. In B.M. Ferdman \& B.R. Deane (Eds.), Diversity at work: The practice of inclusion (pp. 229-259). San Francisco, CA: Jossey-Bass.

Pearce, J.L., \& Randel, A.E. (2004). Expectations of organizational mobility, workplace social inclusion, and employee job performance. Journal of Organizational Behavior, 25(1), 8198. https://doi.org/10.1002/job.232

Roberson, Q.M. (2006). Disentangling the Meanings of Diversity and Inclusion in Organizations. Group \& Organization Management, 31(2), 212 236. https://doi.org/10.1177/1059601104273064

Sabharwal, M., Levine, H., D’Agostino, M., \& Nguyen, T. (2019). Inclusive work practices: turnover intentions among lgbt employees of the U.S. federal government. The American Review of Public Administration, 49(4), 482-494. https://doi.org/10.1177/0275074018817376

Sabharwal, M. (2014). Is diversity management sufficient? organizational inclusion to further performance. Public Personnel Management, 43(2), 197-217. https://doi.org/10.1177/0091026014522202

Shore, L.M., Cleveland, J.N., \& Sanchez, D. (2018). Inclusive workplaces: a review and model. Human Resource Management Review, 28(2), 176-189. https://doi.org/10.1016/j.hrmr.2017.07.003 
Shore, L.M., Randel, A.E., Chung, B.G., Dean, M.A., Holcombe Ehrhart, K., \& Singh, G. (2011). Inclusion and diversity in work groups: A review and model for future research. Journal of Management, 37(4), 1262-1289. https://doi.org/10.1177/0149206310385943

Smith, C., \& Yoshino, K. (2019). Deloitte. Uncovering Talent: A new model of inclusion. Retrieved from https://www2.deloitte.com/content/dam/Deloitte/us/Documents/about-deloitte/us-about-deloitteuncovering-talent-a-new-model-of-inclusion.pdf

Techstars Startup Ecosystems Development Program. (2019, March). Roadmap \& Assessment Report. Retrieved from https://media.bizj.us/view/img/11267413/12-louisville-ky-roadmap-andassessment-final-reportdigitalpublic-use-approved.pdf

The Gallup Corporation. (2018). Gallup's Approach to Culture: Building a Culture That Drives Performance. Retrieved from https://www.gallup.com/workplace/232682/culture-paper2018.aspx

U.S. Chamber of Commerce Foundation. (2019, April). Business Success and Growth through LGBTinclusive culture. Retrieved from https://www.uschamberfoundation.org/sites/default/files/Business-Success-Growth-LGBTInclusive-Culture-FINAL-WEB.pdf

\section{APPENDIX 1}

\section{Search Terms}

1. employee inclusion OR "diversity and inclusion" OR "diversity \& inclusion"

2. inclusion OR inclusivity [title/abstract]

3. measure OR metric OR intervention OR model OR framework OR index OR instrument OR survey

4. organization OR employer OR company OR corporation OR workplace OR firm OR "human resources"

5. 1 AND 3 AND 4

6. 2 AND 3 AND 4

\section{APPENDIX 2}

Mor Barak Inclusion/Exclusion Scale (MBIE) (Mor Barak, 2005).

Assessed on a five-point Likert scale ranging from 1 (strongly disagree) to 5 (strongly agree)

\section{Work Group}

Q1: I have influence in decisions taken by my work group regarding our tasks.

Q2: My coworkers openly share work-related information with me.

Q3: I am typically involved and invited to actively participate in work-related activities of my work group.

\section{Organization}

Q4: I am able to influence decisions that affect my organization.

Q5: I am usually among the last to know about important changes in the organization. (R).

Q6: I am usually invited to important meetings in my organization.

\section{Supervisor}

Q7: My supervisor asks for my opinion before make important decisions. 
Q8: My supervisor does not share information with me. (R).

Q9: I am invited to actively participate in review and evaluation meetings with my supervisor.

Higher Management

Q10: I am often invited to contribute my opinion in meetings with management higher than my immediate supervisor.

Q11: I frequently receive communication from management higher than my immediate supervisor.

Q12: I am often invited to participate in meetings with management higher than my immediate supervisor.

\section{Social/Informal}

Q13: I am often asked to contribute in planning social activities not directly related to my job function.

Q14: I am always informed about informal social activities and company social events.

Q15: I am rarely invited to join my coworkers when they go for lunch or drinks after work. (R).

* The respondent is asked to evaluate his or her inclusion across three dimensions: (1) the decision- making process (items 1, 4, 7, 10, 13) (2) information networks (items 2, 5, 8, 11, 14), and (3) level of participation/involvement (items 3, 6, 9, 12, 15).

* Items 5, 8, and 15 are reverse scored.

\section{APPENDIX 3}

\section{Workplace Social Inclusion Scale (Pearce and Randel, 2004)}

Assessed on a five-point Likert scale ranging from 1 (strongly disagree) to 5 (strongly agree)

Q1: I feel like an accepted part of a team.

Q2: I feel included in most activities at work.

Q3: Sometimes I feel like an outsider,

\section{APPENDIX 4}

Climate for Inclusion Scale (Nishii, 2013).

Assessed on a five-point Likert scale ranging from 1 (strongly disagree) to 5 (strongly agree)

\section{Dimension 1: Foundation of equitable employment practices}

1. This [unit] is committed to having diverse employees well-distributed throughout the organization.

2. The employment/HR practices of this [unit] are fairly implemented.

3. This [unit] has a fair promotion process.

4. The performance review process is fair in this [unit].

5. In this [unit], the unique needs of employees are met by flexible benefit programs.

6. This [unit] invests in the development of all of its employees.

7. Employees in this [unit] receive "equal pay for equal work."

8. This [unit] provides safe ways for employees to voice their grievances.

9. People in this [unit] can count on receiving a fair performance review. 


\section{Dimension 2: Integration of differences}

1. In this [unit], employees are comfortable being themselves.

2. This [unit] is characterized by a non-threatening environment in which people can reveal their "true" selves.

3. Promoting diversity awareness is a priority of this [unit].

4. This [unit] values work-life balance.

5. In this [unit], people's differences are respected

6. Employees in this organization are actively encouraged to take advantage of work-life balance programs.

7. This [unit] commits resources to ensuring that employees are able to resolve conflicts effectively.

8. Employees of this [unit] are valued for who they are as people, not just for the jobs that they fill.

9. In this [unit], people often share and learn about one another as people.

10. This [unit] has a culture in which employees appreciate the differences that people bring to the workplace.

11. Intergroup relations (i.e., between different races, workgroups, age groups, etc.) tend to be characterized by respect and trust within this [unit].

\section{Dimension 3: Inclusion in decision making}

1. In this [unit], employee input is actively sought.

2. It is clear that this [unit] perceives employee input as a key to its success.

3. Employees in this [unit] are empowered to make work-related decisions on their own.

4. In this [unit], people's ideas are judged based on their quality, and not based on who expresses them.

5. This [unit] has a climate for healthy debate.

6. In this [unit], everyone's ideas for how to do things better are given serious consideration.

7. Employees in this [unit] are encouraged to offer ideas on how to improve operations outside of their own areas.

8. In this [unit], employees' insights are used to rethink or redefine work practices

9. Top management exercises the belief that problem-solving is improved when input from different roles, ranks, and functions is considered.

10. Employees in this [unit] engage in productive debates in an effort to improve decision making.

11. This is an [unit] in which employees make use of their own knowledge to enhance their work.

\section{APPENDIX 5}

\section{New Inclusion Quotient (IQ)—2015 Federal Employee Viewpoint Survey (FEVS) \\ (Sabharwal et al., 2019).}

Assessed on a three-point scale: (1) negative (2) neutral (3) positive

\section{Fair: Are all employees treated equally?}

Q23: In my work unit, steps are taken to deal with a poor performer who cannot or will not improve.

Q24: In my work unit, differences in performance are recognized in a meaningful way.

Q25: Awards in my work unit depend on how well employees perform their jobs.

Q37: Arbitrary action, personal favoritism and coercion for partisan political purposes are not tolerated.

Q38: Prohibited Personnel Practices (for example, illegally discriminating for or against any employee/applicant, obstructing a person's right to compete for employment, knowingly violating veterans' preference requirements) are not tolerated. 
2. Open: Does management support diversity in all ways?

Q32: Creativity and innovation are rewarded.

Q34: Policies and programs promote diversity in the work- place (for example, recruiting minorities and women, training in awareness of diversity issues, mentoring).

Q45: My supervisor is committed to a workforce representative of all segments of society.

Q55: Supervisors work well with employees of different backgrounds.

3. Cooperative: Does management encourage communication and collaboration?

Q58: Managers promote communication among different work units (for example, about projects, goals, needed resources).

Q59: Managers support collaboration across work units to accomplish work objectives.

4. Supportive: Do supervisors value employees?

Q42: My supervisor supports my need to balance work and other life issues.

Q46: My supervisor provides me with constructive suggestions to improve my job performance.

Q48: My supervisor listens to what I have to say.

Q49: My supervisor treats me with respect.

Q50: In the last 6 months, my supervisor has talked with me about my performance.

5. Empowering: Do employees have the resources and support needed to excel?

Q2: I have enough information to do my job well.

Q3: I feel encouraged to come up with new and better ways of doing things.

Q11: My talents are used well in the workplace.

Q30: Employees have a feeling of personal empowerment with respect to work processes.

\section{APPENDIX 6}

\section{Organizational Inclusion Behaviors Scale (Sabharwal, 2014).}

A. Commitment from top leadership to foster inclusion: In my organization, senior management. . . Is committed to hiring a workforce that is representative of all segments of society.

Has policies and programs in place to promote diversity in the workplace.

Works well with employees of different backgrounds.

Incorporates diversity into the organization's vision or mission statement.

Tries to create an awareness and appreciation of individual and cultural differences among employees. Helps employees understand their own feelings and attitudes about people who are different.

Is held responsible for getting high performance from all their staff. 


\section{B. Ability to influence organizational decisions: My supervisor ...}

Involves me in decisions about my job.

Encourages all employees to express their opinions.

Creates a synergistic approach to problem-solving and decision-making.

Seeks my input before making important organizational decisions.

Provides me with all information and resources that will help me make decisions about my job.

Involves me in decisions about ways to improve productivity.

Involves me in decisions about ways to improve quality of the work environment.

\section{Fairness/equitable treatment: My supervisor ... .}

Evaluates employees fairly.

Has a track record of promoting employees objectively.

Takes action when employees show disrespect for each other.

Assigns tasks based on the knowledge, skills, and abilities possessed by individual employees.

Has fairly rewarded me considering my responsibilities.

Has fairly rewarded me considering the amount of experience I have.

Has fairly rewarded me when I consider the amount of effort that I have put forth.

Has fairly rewarded me for the work well done.

Has fairly rewarded me considering the stresses and strains of the job.

\section{APPENDIX 7}

MODEL OF INCLUSIVE ORGANIZATIONS

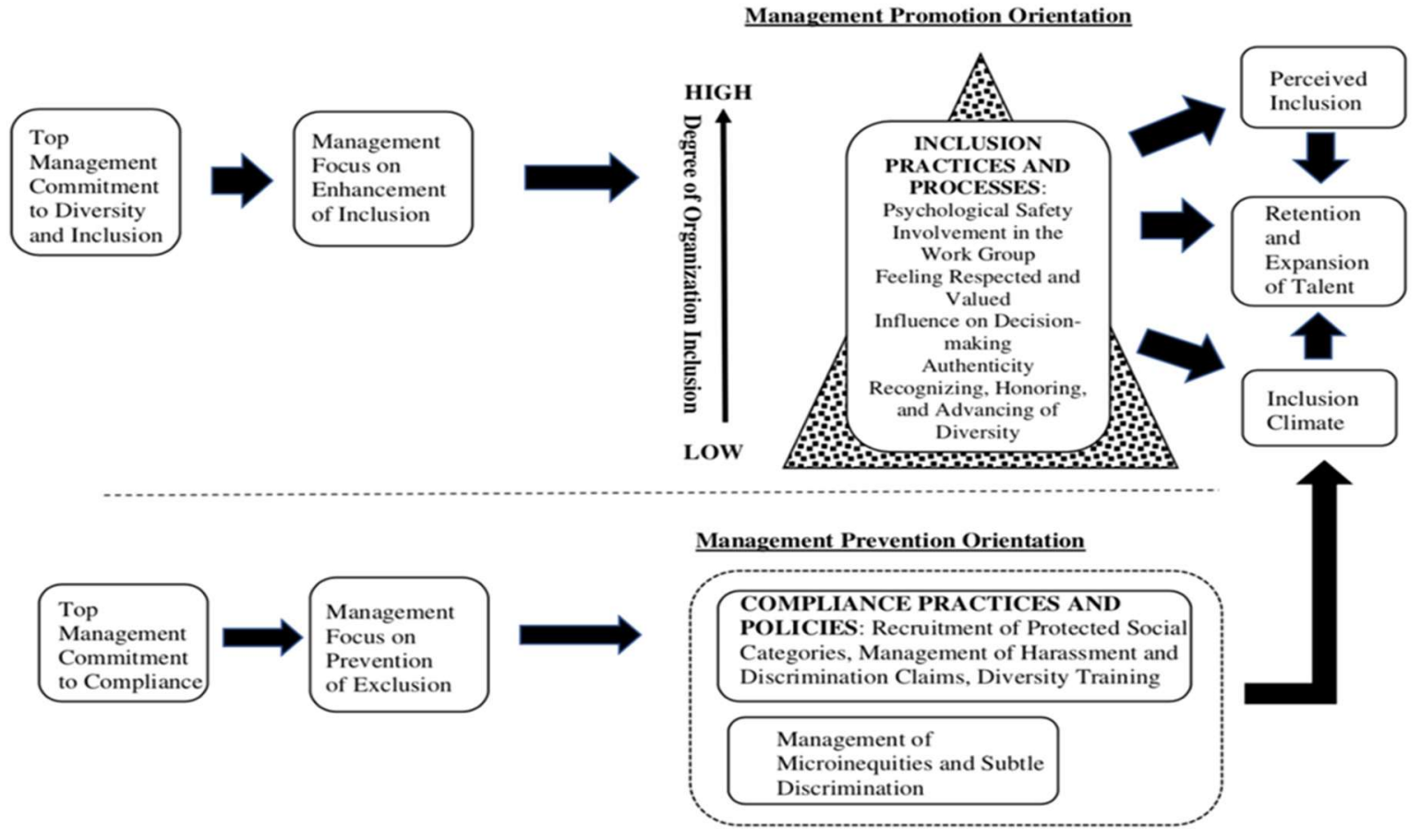

(Shore et al., 2018). 


\section{APPENDIX 8}

\section{BELONGINGNESS/UNIQUENESS INCLUSION FRAMEWORK}

\begin{tabular}{|c|c|c|}
\hline & Low Belongingness & High Belongingness \\
\hline $\begin{array}{l}\text { Low Value in } \\
\text { Uniqueness }\end{array}$ & $\begin{array}{l}\text { Exclusion } \\
\text { Individual is not treated as an } \\
\text { organizational insider with unique } \\
\text { value in the work group but there are } \\
\text { other employees or groups who are } \\
\text { insiders. }\end{array}$ & $\begin{array}{l}\text { Assimilation } \\
\text { Individual is treated as an insider in the } \\
\text { work group when they conform to } \\
\text { organizational/dominant culture } \\
\text { norms and downplay uniqueness. }\end{array}$ \\
\hline $\begin{array}{l}\text { High Value in } \\
\text { Uniqueness }\end{array}$ & $\begin{array}{l}\text { Differentiation } \\
\text { Individual is not treated as an } \\
\text { organizational insider in the work } \\
\text { group but their unique characteristics } \\
\text { are seen as valuable and required for } \\
\text { group/ organization success. }\end{array}$ & $\begin{array}{l}\text { Inclusion } \\
\text { Individual is treated as an insider and } \\
\text { also allowed/encouraged to retain } \\
\text { uniqueness within the work group. }\end{array}$ \\
\hline
\end{tabular}

(Shore et al., 2011)

\section{APPENDIX 9}

\section{Downey Inclusion Scale* (Downey et al., 2015).}

Assessed on a five-point Likert scale ranging from 1 (strongly disagree) to 5 (strongly agree)

Q1: I believe that I play an important role in helping to shape the policies, procedures, and practices of [the organization].

Q2: All viewpoints, including those that differ from the majority opinion, are considered before decisions are made by [the organization].

Q3: My co-workers show their appreciation for the contributions I make to our department.

Q4: At [the organization], everyone works closely together to accomplish the goals of the medical center.

Q5: Everyone at [the organization], regardless of background and perspective, is encouraged to share their ideas openly.

\section{*Study did not provide full scale but gave five sample items.}

\section{APPENDIX 10}

\section{Work Group Inclusion Measure with Belongingness and Uniqueness}

Assessed on a five-point Likert scale ranging from 1 (strongly disagree) to 5 (strongly agree)

I am treated as a valued member of my work group. (B)

I belong in my work group. (B)

I am connected to my work group. (B) 
I believe that my work group is where I am meant to be. (B)

I feel that people really care about me in my work group. (B)

I can bring aspects of myself to this work group that others in the group don't have in common with me.

(U)

People in my work group listen to me even when my views are dissimilar. (U)

While at work, I am comfortable expressing opinions that diverge from my group. (U)

I can share a perspective on work issues that is different from my group members. (U)

When my group's perspective becomes too narrow, I am able to bring up a new point of view. (U)

* $B=$ belongingness component of work group inclusion; $U=$ uniqueness component of work group inclusion.

\section{APPENDIX 11}

\section{Individual Inclusion Experience}

Assessed on a four-point Likert scale ranging from 1 (never) to 5 (always)

The study did not provide the exact wording used in the measure, but did provide "Respondents were asked to indicate the extent to which they were comfortable voicing ideas, opinions, and discussing issues of diversity, felt valued and encouraged to be themselves by other board members, and felt they had the same opportunities as others for leadership and officer positions" (Pearce and Randel, 642). Below are the items presumed to be included:

Q1: Ifeel comfortable voicing ideas and opinions

Q2: I feel comfortable discussing issues of diversity.

Q3: I feel valued and encouraged to be myself by other board members

Q4: I feel I have the same opportunities as others for leadership and officer positions. 